\title{
Resolvins in inflammation: emergence of the pro-resolving superfamily of mediators
}

\author{
Charles N. Serhan ${ }^{1}$ and Bruce D. Levy ${ }^{2}$ \\ ${ }^{1}$ Center for Experimental Therapeutics and Reperfusion Injury, Department of Anesthesiology, Perioperative and Pain Medicine, and ${ }^{2}$ Pulmonary and Critical Care Medicine, Department of Medicine, Brigham \\ and Women's Hospital and Harvard Medical School, Boston, Massachusetts, USA.
}

Countless times each day, the acute inflammatory response protects us from invading microbes, injuries, and insults from within, as in surgery-induced tissue injury. These challenges go unnoticed because they are self-limited and naturally resolve without progressing to chronic inflammation. Peripheral blood markers of inflammation are present in many common diseases, including inflammatory bowel disease, cardiovascular disease, neurodegenerative disease, and cancer. While acute inflammation is protective, excessive swarming of neutrophils amplifies collateral tissue damage and inflammation. Hence, understanding the mechanisms that control the resolution of acute inflammation provides insight into preventing and treating inflammatory diseases in multiple organs. This Review focuses on the resolution phase of inflammation with identification of specialized pro-resolving mediators (SPMs) that involve three separate biosynthetic and potent mediator families, which are defined using the first quantitative resolution indices to score this vital process. These are the resolvins, protectins, and maresins: bioactive metabolomes that each stimulate self-limited innate responses, enhance innate microbial killing and clearance, and are organ-protective. We briefly address biosynthesis of SPMs and their activation of endogenous resolution programs as terrain for new therapeutic approaches that are not, by definition, immunosuppressive, but rather new immunoresolvent therapies.

Protection versus uncontrolled inflammation: first responders and resolution

New evidence indicates that uncontrolled inflammation is a prominent component of many common diseases, including wellknown inflammatory diseases such as arthritis and periodontal disease as well as inflammatory bowel disease, cardiovascular disease, the neurodegenerative diseases Alzheimer's and Parkinson's, asthma, cancer, metabolic syndromes (e.g., obesity), diabetes, and autoimmune diseases (https://www.cdc.gov). In each, peripheral blood markers of inflammation are present and elevated (1). Aging and proinflammatory nutrition $(2,3)$ also contribute to increases in inflammatory markers. Thus, the impact of uncontrolled inflammation on the United States alone is estimated in hundreds of millions of dollars for each disease, with substantial increases by 2030 - certainly, epidemic proportions.

The acute inflammatory response is protective. Among the first responders, neutrophils (polymorphonuclear leukocytes [PMNs]) leave postcapillary venules to phagocytize microbes and cellular debris (4). PMNs neutralize and clear invaders; however, when excess PMNs congregate or swarm in tissues

Conflict of interest: The authors are inventors on patent applications and awarded patents assigned to Brigham and Women's Hospital; some are licensed for clinical development (US patents 7,585,856; 6,670,396; 7,053,230; 7,709,669; 7,737,178; 8,349,896; 7,030,159; 7,741,368; 7,341,840; 7,803,557; 8,927,747; 9,611,238; 9,611,239; and 9,611,240 to CNS; and US patents 7,759,395; 7,872,152; 8,569,542; 8,933,270; 7,759,395; 7,872,152; $8,569,542 ; 8,273,792 ; 8,273,792 ;$ and $8,933,270$ to CNS and BDL). Reference information: J Clin Invest. 2018;128(7):2657-2669. https://doi.org/10.1172/JC197943.
(5), they can inadvertently release their antimicrobial armamentarium via frustrated phagocytosis or cell death $(4,6)$, leading to tissue damage that amplifies inflammation and continues to chronicity. PMN-driven inflammation is a unifying mechanism for many diseases and reperfusion second-organ injury (4). Hence, it is critical to appreciate mechanisms and specialized mediators (7) involved in resolution and whether we can use these to control inflammation.

In health, acute inflammatory response(s) are self-limited, as in surgery-induced tissue injury, in that they resolve on their own and classically divide into initiation and resolution phases (4). To date, we view acute inflammation as a temporal crescendo to resolution and decrescendo of initiating chemical mediator gradients (7). In resolution (Figure 1), the host response is active (7) and not simply a passive dilution of proinflammatory mediators (8), enabling tissues to restore function (4). Lipoxins biosynthesized from arachidonic acid are potent, active stop signals for PMN infiltration $(9,10)$ and are produced during resolution of self-limited inflammatory responses $(11,12)$.

While current treatments for inflammation can be effective, many eventually become immunosuppressive opportunities for infection. Chemical mediators such as prostaglandins physiologically mediate the cardinal signs of inflammation (color, rubor, tumor, dolor) and are effectively controlled by traditional NSAIDs (13); however, NSAIDs are not without unwanted side effects. Given the significant public health impact of inflammation-associated diseases, it is paramount to seek new treatments and mechanisms controlling inflammation and collateral tissue damage from excessive PMN swarming (5). In 


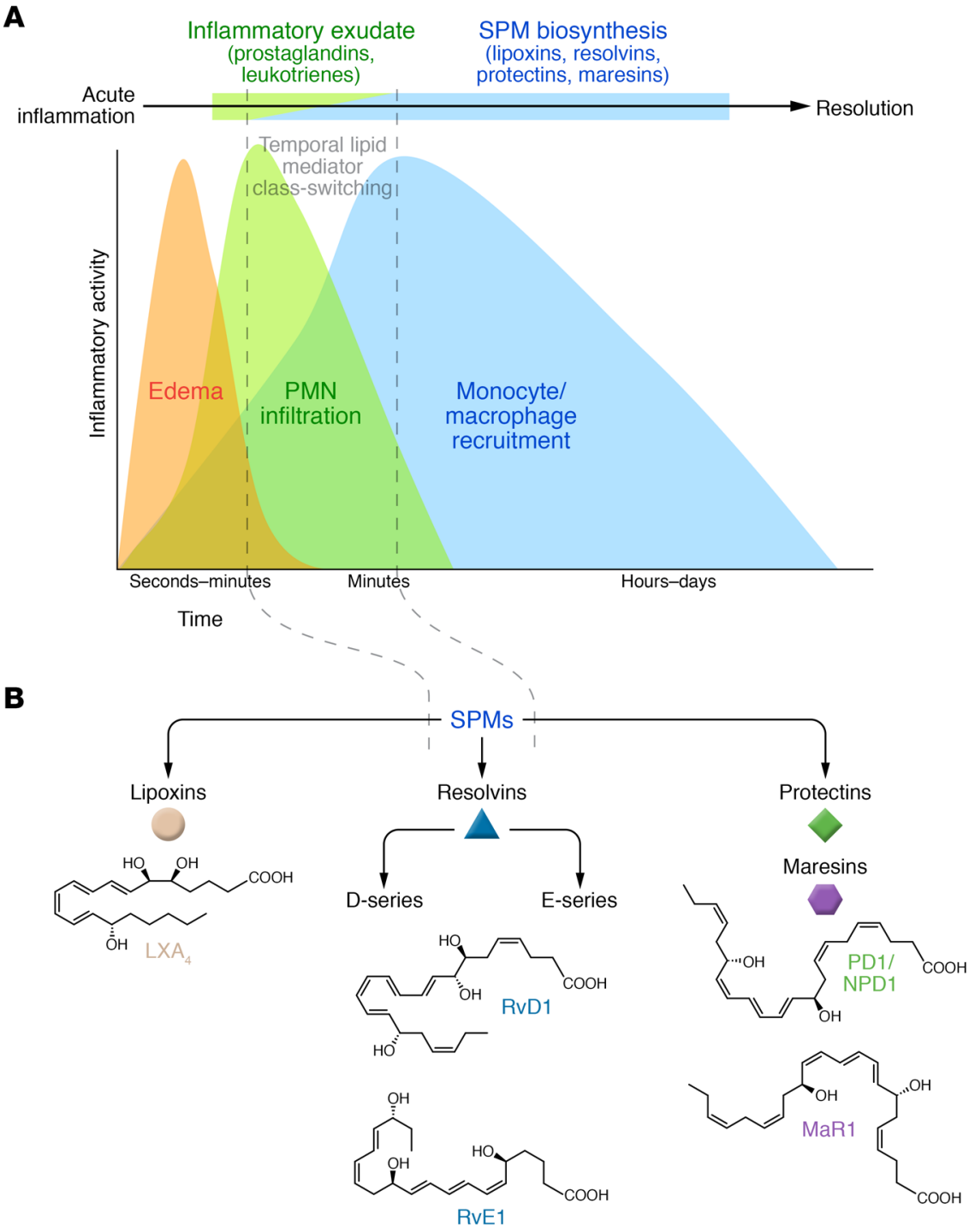

Figure 1. Acute inflammatory response and its ideal outcome: complete resolution. (A) Temporal lipid mediator class-switching initiates active resolution and SPM biosynthesis. Defined steps in the acute inflammation time course: edema, PMN infiltration, and then non-phlogistic monocytemacrophage recruitment to inflammatory exudates. The reduction in PMN number coincides with the exudate appearance of SPMs and with the biosynthesis of lipoxins, resolvins (E- and D-series), protectins, and maresins in resolving exudates. (B) Each family of SPMs is structurally distinct and possesses potent pro-resolving actions.

this mini-series Review, we briefly address active endogenous resolution programs and novel resolution mediators as promising terrain for new therapeutic approaches (7) that would serve as immunoresolvents rather than immunosuppressants (14) - namely, pro-resolving agonists that stimulate resolution as pharmacologic agents $(7,15-18)$. We provide here a brief overview and update with key points from recent advances to complement other in-depth reviews $(7,15-17,19,20)$.

\section{Specialized novel mediators in resolution}

Chemical mediators govern cellular traffic, and those derived from essential polyunsaturated fatty acids (PUFAs) are most potent. Leukotriene $\mathrm{B}_{4}\left(\mathrm{LTB}_{4}\right)$ is a chemoattractant (21) and main mediator of PMN swarming (5). Using a systems approach, we compared human pleural and PMN-rich exudates to time course studies from mouse air-pouch exudates and their resolution. We found a temporal lipid mediator class switch (11) where cyclooxygenase-derived prostaglandin $\mathrm{E}_{2}\left(\mathrm{PGE}_{2}\right)$ antecedes biosynthesis of lipoxins. Human PMNs exposed to $\mathrm{PGE}_{2}$ or $\mathrm{PGD}_{2}$ induced 15-lipoxygenase (15-LOX) switching phenotype from $\mathrm{LTB}_{4}$ production to lipoxin production, which is a PMN stop signal that limits further recruitment (11). This PMN phenotype switch marks the resolution phase, because lipoxin $\mathrm{A}_{4}\left(\mathrm{LXA}_{4}\right)$ also stimulates macrophage efferocytosis (phagocytosis of apoptotic PMNs and debris) (6, 7, $18,19)$. Using lipid mediator metabololipidomics, proteomics (liquid chromatographytandem mass spectrometry [LC-MS/MS]), and cell trafficking in self-limited exudates, we identified three new families of mediators (9, 22-24), coined "resolvins" (short for resolution phase interaction products), "protectins," and "maresins" (short for macrophage mediators in resolving inflammation) (25). Each is structurally distinct (Figure 2), biosynthesized from eicosapentaenoic acid (EPA), docosapentaenoic acid (n-3DPA), or docosahexaenoic acid (DHA) $(7,23,26,27)$. EPA-derived 18-HEPE and 15-HEPE are produced by hypoxic vascular endothelial cells and reduce PMN transendothelial migration, but are less potent than resolvin E1 (RvE1) or 15-epi-LXA (9). Diapedesis or transendothelial migration is the committed step for PMN recruitment to inflamed sites (4). Both 18-HEPE and RvE1 are antiinflammatory, stopping PMN migration and stimulating resolution (9). Aspirin triggers their biosynthesis (Figure 2), and acetaminophen and indomethacin also permit 18-HEPE production, whereas selective cyclooxygenase-2 (COX-2) inhibitors block 18-HEPE production. These findings provided new mechanism(s) for aspirin's well-appreciated benefits $(19,28)$. It was deemed critical to establish defining criteria for pro-resolving actions to qualify and validate these new molecules to direct elucidation of biosynthesis and structure (Table 1).

In addition to biosynthesis of lipoxins and their aspirintriggered 15-epimeric forms (reviewed in ref. 19), newer n-3 PUFA-derived bioactive metabolomes for resolvins, protectins, and maresins (7) are depicted in Figure 2. Because each family member possesses potent pro-resolving and antiinflammatory actions (recently reviewed in refs. 7, 29) with special functions in the resolution phase (Table 1), this superfamily is coined "specialized pro-resolving mediators" (SPMs). Each carries defining biological functions with cell type- and organ-specific properties, reflecting stereospecific activation of cellular receptors (30). The 
Resolvin family, E-series

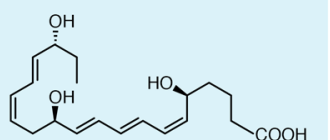

RvE1
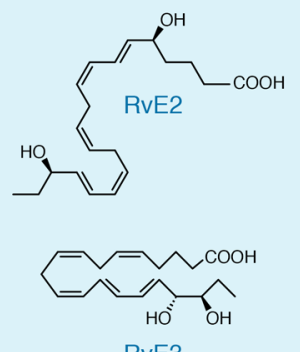

RvE3

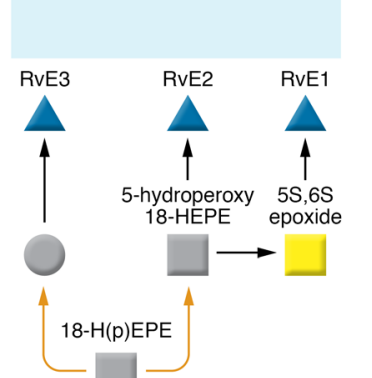

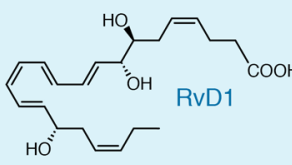

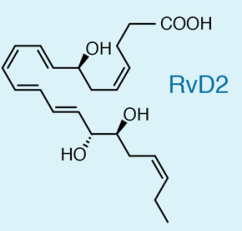

HO"

Resolvin family, D-series

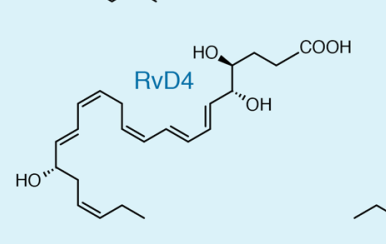

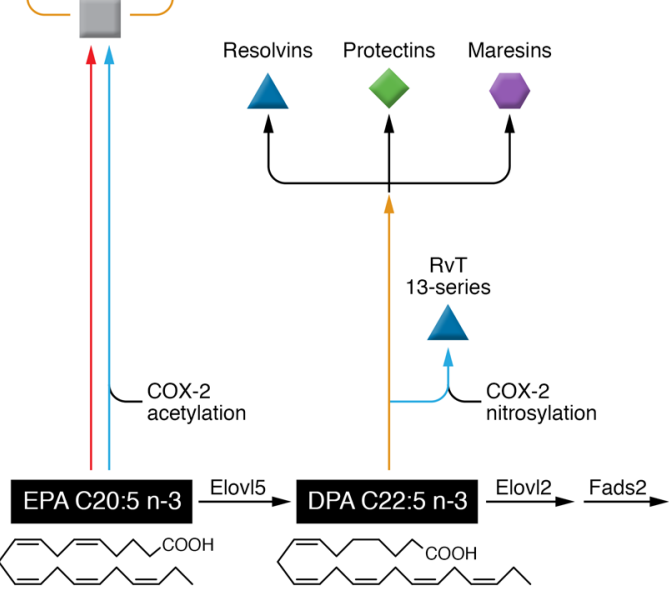

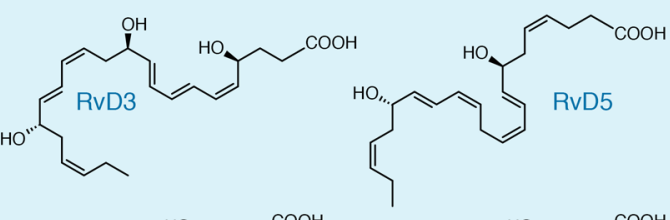
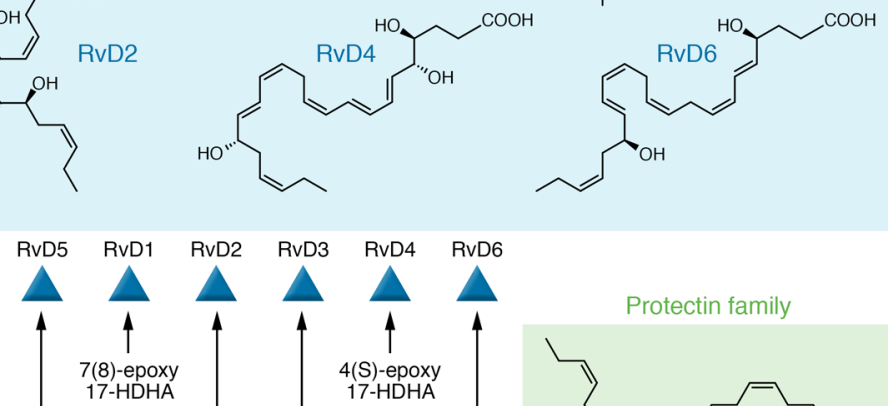

Protectin family
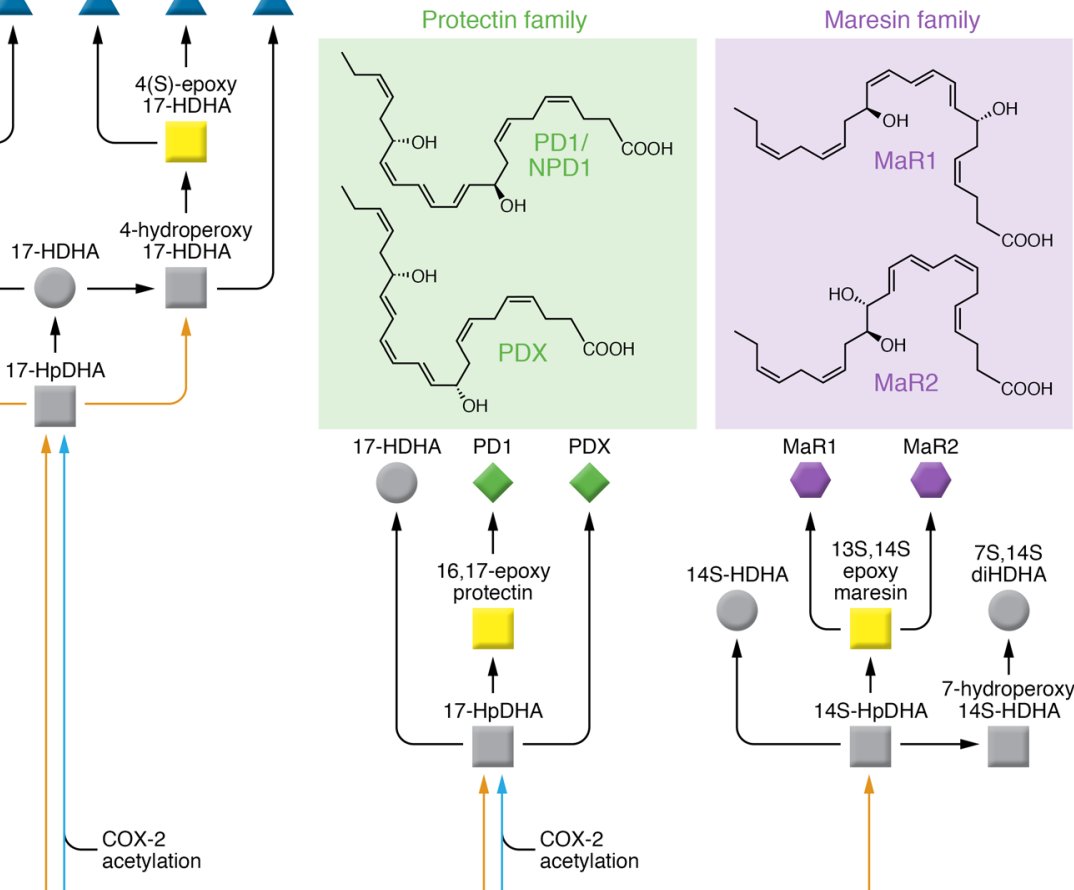

protectin

cetylation

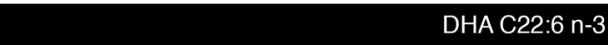

DHA C22:6 n-3
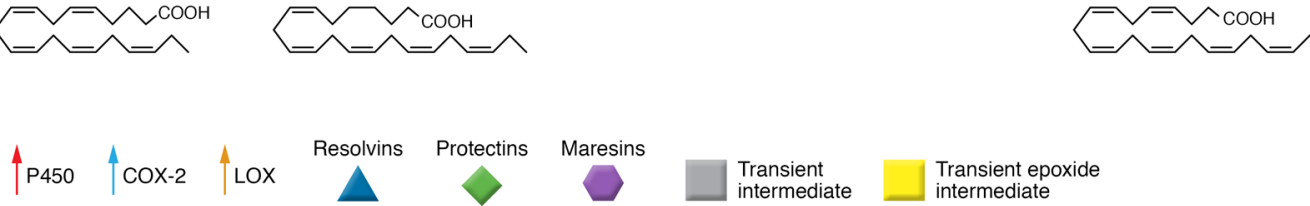

Figure 2. SPM network biosynthetic metabolomes. Network illustration of the enzymes, intermediates, and precursors of the SPM superfamily's biosynthesis from omega-3 PUFA. Deficiencies in the fatty acid desaturase (Fads) gene cluster reduce SPM production (194). Stereochemistry of each major SPM is established; for detailed mechanisms in biosynthesis and complete SPM nomenclature of each endogenous molecule, see refs. 36, 39, 41-43, and 58 and those within.

main biosynthesis routes were each confirmed via trapping of intermediates and label-tracking of precursors and intermediates. In addition to lipoxygenase-initiated pathways that produce mediators with alcohols, e.g., PD1/NPD1 or D-series resolvins (RvDs) in predominantly $17 \mathrm{~S}$ configuration, aspirin acetylation of COX-2 produces intermediates in the R configuration at the 17-carbon position, giving 17R epimers or 17R-PD1 and RvDs, coined as aspirintriggered protectin and resolvin mediators $(23,31)$. SPM R-epimers are longer-acting. Statins also lead to COX-2 $S$-nitrosylation that, like aspirin, changes the enzyme's catalysis to produce predominantly R-epimer-containing intermediates, exemplified by novel 13-series resolvins (RvTs) from vascular n-3DPA (26). The complete stereochemistry and biosynthesis of each SPM are established (3243), as are epoxy-intermediates of maresins and protectins (36).

Resolvins are produced from DHA, n-3DPA, and EPA (Figure 2), marine oils that enter humans via nutrition or supplementation (3). The term "resolvin" refers to the unique structures, temporal code in biosynthesis during resolution, and potent pico-nanogram 


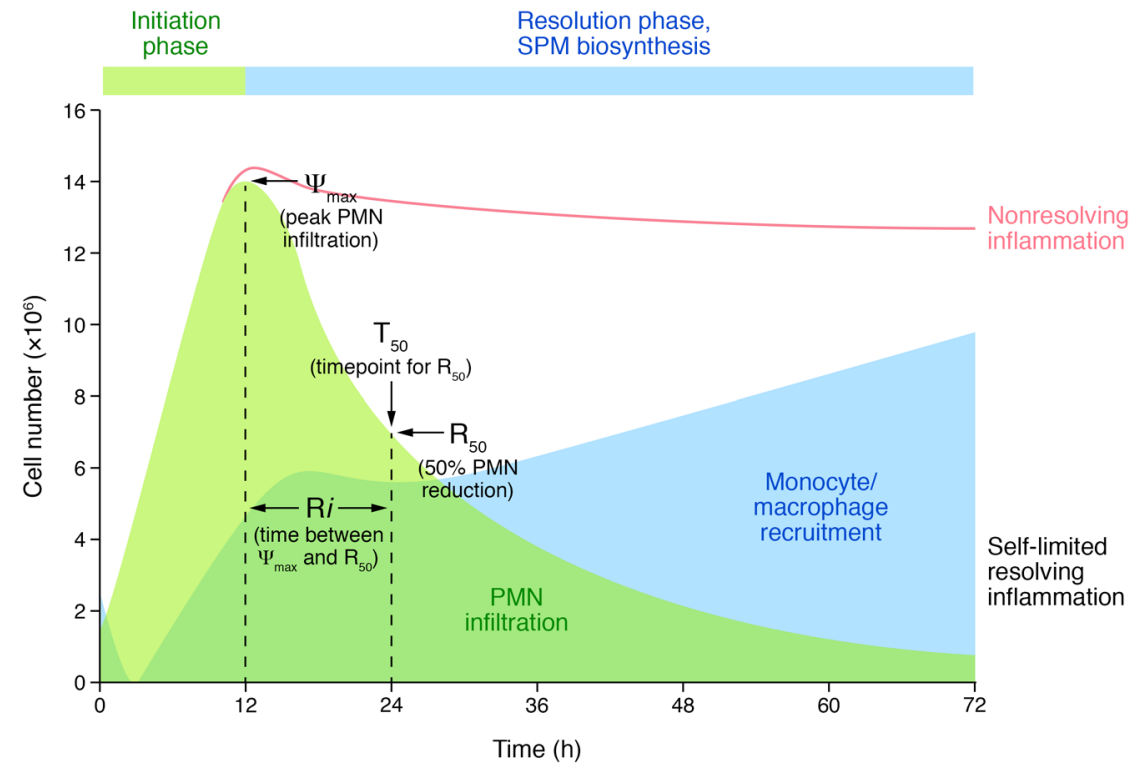

Figure 3. Quantitative definition of exudate resolution and non-resolving inflammation. Hypothetical example of contained self-limited resolving inflammation versus non-resolving inflammation (red line) to illustrate the quantitative indices and components: $\psi_{\text {max }}$ for peak PMN infiltration, $50 \%$ of peak PMN $\left(R_{50}\right)$, time point of $R_{50}\left(T_{50}\right)$, and resolution interval (Ri) to quantitate PMN influx and removal as well as non-phlogistic recruitment of monocytes-macrophages in exudates, which is required for repair and renewed function. See text and refs. 22 and 85 for original results and definitions.

ability to counterregulate proinflammatories and actively promote resolution via monocyte/macrophage uptake of debris, apoptotic PMNs, and killing/clearing microbes $(23,37,38)$. RvEs from EPA (18-HEPE, RvE1, RvE2, and RvE3) have four main bioactive mediators, biosynthesized as either $18 \mathrm{R}$ or $18 \mathrm{~S}$ epimers (38) with activity in pico-nanogram ranges that is not shared by their precursor EPA. RvE1 downregulates leukocyte adhesive molecules (i.e., CD11/ CD18) and ADP-dependent platelet activation $(44,45)$. RvE1 promotes PMN apoptosis to accelerate resolution (46). Human PMN RvE2 biosynthesis is enhanced in hypoxia (47), 18-HEPE is cardioprotective (48), and RvE3 stops PMNs (49). RvE1 reduces dendritic cells' IL-12 production (32) and, in skin, attenuates contact hypersensitivity (50). RvE1 and RvE2 biosynthesis involves 5-LOX, pro-

\section{Table 1. Pro-resolving mediators: defining physiologic actions in the signs of resolution}

Temporal stereospecific biosynthesis via leukocyte exudate traffic
Cessation of PMN infiltration; stop signals to limit further PMN recruitment and PMN-
mediated tissue damage
Enhancement of macrophage phagocytosis of apoptotic PMNs and cellular debris and
augmentation of bacteria killing by phagocytes
Actions at both transcriptional and translational level, microRNA
Actions via specific receptors in the pico-nanomolar range in a stereoselective fashion
Shortening of time to resolution (resolution interval $\mathrm{R}_{i}$ ) by activation of endogenous
resolution programs
Resolution and reduction of pain

Temporal stereospecific biosynthesis via leukocyte exudate traffic

Cessation of PMN infiltration; stop signals to limit further PMN recruitment and PMNmediated tissue damage

Enhancement of macrophage phagocytosis of apoptotic PMNs and cellular debris and augmentation of bacteria killing by phagocytes

Actions at both transcriptiona and translation

Shortening of time to resolution (resolution interval R) by activation of endogenous

Resolution and reduction of pain ducing an 18-hydroxy-5(6)-epoxide via LTA $_{4}$ hydrolase that is converted to RvE1, and 5-LOX converts 18-HEPE to RvE2; RvE1 and RvE2 each potently stimulate IL-10 and phagocytosis $(38,51)$.

RvD1-RvD6 are biosynthesized in exudates and by human PMNs and macrophages (23, 52) via two separate allylic epoxide-containing intermediates (Figure 2). RvD1 and RvD2 are biosynthesized from a 17-hydroperoxy product of 15-LOX with substrate DHA. This intermediate is converted to either 7(8)-epoxytetraeneintermediate or RvD5 via 5-LOX (35). RvD2 also carries potent organ-protective actions and enhances bacterial killing/clearance (53). RvD1 protects from PMN-mediated reperfusion organ injury (54). In exudates, RvD1 and RvD2 appear in the onset of resolution followed by RvD3 and RvD4 from a 4(5)epoxideintermediate $(14,55,56)$. Each stereochemistry is confirmed $(14,39,55-57)$.

Protectin biosynthesis and maresin biosynthesis (Figure 2) each proceed via epoxide intermediates critical to attain the stereochemistry of their potent mediators (58). Protectin D1 (PD1) is enzymatically produced by human leukocytes from 16(17)epoxide-intermediate (34). In addition to PMNs, macrophages $(34,52)$ and eosinophils $(59,60)$ produce $\mathrm{PD} 1$, and its production is reduced in patients with severe asthma $(61,62)$. The double lipoxygenase product $10,17-$ diHDHA is obtained by two sequential steps with reduction of hydroperoxide-intermediate(s) giving 10S,17S-diHETE (34) coined PDX, an isomer of PD1, which has several actions (63-66) but whose receptor remains unknown. PD1 when produced in neural systems is termed neuroprotectin D1 (NPD1/PD1) and demonstrates potent protective actions in retina, brain, and pain $(67,68)$.

Maresin biosynthesis is initiated at carbon-14 via human 12-LOX $(25,69)$, producing a $13(14)$ epoxide-intermediate (eMaR) that stimulates M1 conversion to M2 macrophages and blocks LTA $_{4}$ hydrolase (70). The stereochemistry of the products maresin 1 (MaR1) and MaR2 is established, with actions in pain and tissue regeneration $(33,70)$.

Substrate flow. Resolving secretory phospholipases, sPLA2IID and sPLA2-III, release DHA and n-3DPA from phospholipids with selectivity for SPM production (71). Microparticles are also a source of SPM precursors, e.g., 17-HDHA released via sPLA2 $(52,72)$. These substrates are taken up via nutrition and esterified into phospholipids. The ratio of n-3 to n- 6 is currently used to mark human levels of omega-3 fatty acids obtained from algae and marine organisms as potential membrane sources of SPMs $(3,73,74)$. Omega- 3 fatty acids were thought to block coagulation; however, doses up to $10 \mathrm{~g} / \mathrm{d}$ EPA and DHA or consumption of 1.5 $\mathrm{g} / \mathrm{d}$ for 52 weeks by cancer or ICU patients were found to be safe and without adverse bleeding (75). During resolution of inflammation, non-esterified substrates also flow into exudates via edema carried by proteins (54), which appears to be the major substrate form supplied to the brain (76). 
While appreciated as an intermediate in n-3 PUFA biosynthesis in humans, n-3DPA conversion to DHA appears to be greater in women than men supplemented with $\alpha$-linolenic acid (77). n-3DPA is also a precursor to SPMs, carrying 22 carbons with 5 double bonds (denoted C22:5; Figure 2) as opposed to 6 in DHA (C22:6) (27). These n-3 immunoresolvents are biosynthesized (Figure 2) in three families: resolvin $n_{n-3 D P A}$, protectin $n_{n-3 D P A}$, and $\operatorname{maresin}_{n-3 D P A}$, each demonstrating potent pro-resolving actions (27) in human subjects (78). Rapid advances in the organic synthesis of SPMs from n-3DPA and their matching to endogenous mediators $(36,79)$ facilitated demonstration of potent protection by protectin $\mathrm{D} 1_{\mathrm{n}-3 \mathrm{DPA}}$ and resolvin D5 ${ }_{\mathrm{n}-3 \mathrm{DPA}}$ in colitis (80). Human and mouse tissues treated with the statin atorvastatin convert n-3DPA to RvTs (26). RvTs are organ-protective, enhance phagocytosis and bacterial killing, and regulate inflammasome components. This mechanism involves COX-2 $S$-nitrosylation and transcellular RvT biosynthesis via PMN-endothelial cell interactions that accelerate resolution; RvTs are produced in healthy subjects (26). RvTs activate protective host responses to resolve infection-initiated inflammation (26) and, like resolvins and protectins $(58,81)$, uncover a potential approach to develop host-directed therapies (82).

In addition to transcellular mechanisms, SPM biosynthesis proceeds via HDL interactions with macrophages (83), producing $\mathrm{LXB}_{4}$ and RvE2 from healthy subjects. Macrophages also produce SPMs when interacting with apoptotic PMNs (52) and pro-resolving microparticles (72).

\section{Resolution indices: quantitative definitions for physiology and pharmacology}

Once it was established that lipoxins, aspirin-triggered lipoxins, and their synthetic analogs are antiinflammatory $(7,81)$, a quantitative definition of resolution was needed to account for cellular and molecular mechanisms of novel pro-resolving mediators, because resolution was described only by histology $(4,84)$. This was critical because in self-limited inflammation, the ideal outcome is resolution, a highly coordinated and active process controlled by pro-resolving mediators (84). In addition to pinpointing SPM biosynthesis and actions (Figure 3), resolution indices can also dissect the impact of drugs and infection. Charles Serhan's laboratory introduced quantitative resolution indices focusing on exudate PMNs and macrophages. Quantitation of PMN infiltration, subsequent clearance by apoptosis and efferocytosis, and non-phlogistic monocyte/macrophage recruitment, including their magnitude, duration, and loss from exudates $(22,85)$, gave birth to the resolution interval $\left(\mathrm{R}_{i}\right.$, time interval from maximum PMN influx point $\Psi_{\max }$ to $50 \%$ reduction $\mathrm{R}_{50}$, i.e., $\mathrm{T}_{50}-\mathrm{T}_{\max }$; Figure 3). Resolution indices defined inflammatory catabasis using temporal lipidomics, proteomics, and flow cytometry to establish relationships between eicosanoids, SPMs, and chemokines/cytokines, as well as potential resolver or protein resolution activators (22, $37,85)$. Among the identified resolver proteins are annexin $\mathrm{A} 1$ and annexin I-derived peptides that stimulate resolution (17).

SPMs shorten $\mathrm{R}_{i}$ both by lowering the amplitude of PMN influx $\left(\Psi_{\max }\right)$ and by stimulating clearance by efferocytosis and phagocytosis, microbe killing, and containment $(14,37,86)$. These indices permitted assignment of roles of additional resolution agonists such as erythropoietin (87), plasmin (88), carbon monoxide (89), cyclin-dependent kinase inhibitors (90), annexin peptides (91), and others (17). Since these indices were unavailable at the time of development, some widely used drugs are now recognized as "resolution toxic," i.e., disrupting active resolution programs (20) including NSAIDs and COX-2 inhibitors. These antiinflammatories lower PMN amplitude $\left(\Psi_{\max }\right)$ but lengthen resolution interval $\left(\mathrm{R}_{i}\right)$ by impairing efferocytosis and/or uncoupling $\mathrm{PGE}_{2}$ - and $\mathrm{PGD}_{2}$-dependent lipoxygenase expression (11, $92,93)$. Lipoxygenase inhibitors also increase $\mathrm{R}_{i}$, by decreasing SPMs (85), and lidocaine increases $\mathrm{R}_{i}$ by blocking efferocytosis (94). In contrast, some widely used drugs stimulate resolution and shorten $\mathrm{R}_{i}$. Distinct from NSAIDs, aspirin decreases $\mathrm{R}_{i}$ by acetylating COX-2, contributing to production of the R-epimer lipoxins, resolvins, and protectins $(7,31)$. Other common resolutionpromoting drugs include statins, which increase epimeric SPMs (26), and glucocorticoids, which increase annexin A1 (95) and apoptosis as well as efferocytosis (20) yet can turn immunosuppressive. Hence, resolution indices defined the resolution agonist (Figure 3) properties of resolvins and other SPMs (Figure 2), which are critical for developing new therapeutics that are resolution-friendly. Antiinflammatories clearly have a different mechanism of action than immunoresolvents (Table 1).

\section{SPMs promote resolution in sterile versus infectious inflammation}

Specific SPMs are temporally and differentially regulated during infections and sterile tissue responses to injury. With bacterial infection, SPMs display anti-phlogistic properties and enhance pathogen containment. In contrast to immunosuppression, SPM augmentation of host defense lowers antibiotic requirements for bacterial clearance. Interestingly, RvD1 and RvD5 reduce bacterial titers in blood and exudates, in part by increasing neutrophil and macrophage phagocytosis of bacteria and mediating counterregulation of proinflammatory genes, including those encoding NF- $\kappa \mathrm{B}$ and TNF- $\alpha$ (37). Both RvD1 and ciprofloxacin accelerate resolution of $E$. coli infection, shortening $\mathrm{R}_{i}$; moreover, RvD1's host-directed actions enhance ciprofloxacin's therapeutic effects $(37,96)$. RvD2 is another potent immunoresolvent that is biosynthesized during active tissue resolution programs (53). In both E. coli and Staphylococcus aureus infections, RvD2 limits neutrophil infiltration and enhances phagocyte clearance of bacteria (97). In addition to regulating neutrophil responses to infection, RvD2 mediates protection from neutrophil-initiated secondorgan injury. After sterile injury from ischemia/reperfusion, RvD2 gives marked organ protection with decreased neutrophil infiltration to lungs. In this model, RvD2 administration increases tissue levels of other SPMs in a receptor-mediated manner to propel a positive-feedback loop for resolution (97).

In addition to leukocyte-mediated injury "from within," sterile direct tissue injury by extrinsic means evokes a resolution response in health. In mouse lung injury from gastric acid aspiration, SPM production is temporally regulated with early MaR1 and later RvD1 and RvD3 (98-100). Intravenous administration of MaR1, RvD1, or RvD3 after intrabronchial acid dampens the maximal extent of acute lung inflammation and promotes a more rapid return to homeostasis. RvD1 also protects tissue after hyperoxic lung injury, decreasing oxidative stress and NF-кB. SPMs, includ- 
ing RvD1 and MaR1, can also shorten $\mathrm{R}_{i}$ for lung injury by increasing macrophage heme oxygenase- $1(89,101)$. In these models, SPMs mediate protection via several cellular and organ-level mechanisms, including decreasing neutrophil trafficking and activation, increasing macrophage phagocytosis and efferocytosis, accelerating restitution of epithelial barrier integrity, and enhancing edema clearance (102).

\section{SPMs in transitions between innate and adaptive immunity}

Beyond innate phagocyte responses to resolve acute inflammation, SPMs appear to play critical roles in regulating adaptive immunity. While homeostatic adaptive immune responses are targeted, pathologic adaptive inflammation can become overly exuberant or chronic and nonresolving. SPMs selectively regulate cytokines via SPM receptors expressed on innate lymphoid, NK, T, and B cells. In type 2 innate lymphoid cells, SPMs decrease proinflammatory type 2 cytokine production but increase amphiregulin expression for mucosal protection $(103,104)$. Cytotoxic properties of NK cells can promote granulocyte apoptosis for their clearance, a resolution mechanism augmented by SPMs (103). RvD1 and RvD2 control CD $4^{+} \mathrm{T}$ cell differentiation into Th1 and Th17 effectors with decreased production of the lineage-specific cytokines IFN- $\gamma$ (Th1) and IL-17 (Th17) and their transcription factors T-bet and RORc (105). SPMs also decrease production of IL-2, IFN- $\gamma$, and TNF- $\alpha$ by CD $8^{+} \mathrm{T}$ cells.

To regulate adaptive responses, SPMs such as MaR1 promote de novo generation of FoxP3-expressing regulatory $\mathrm{T}$ cells from naive $\mathrm{CD}^{+} \mathrm{T}$ cells as well as TGF- $\beta$ and amphiregulin expression (104). SPMs have an adjuvant effect on B cells, enhancing humoral immunity. SPMs increase IgM and IgG production from activated human $\mathrm{B}$ cells with differentiation toward a $\mathrm{CD} 27^{+} \mathrm{CD} 38^{+}$ antibody-secreting cell phenotype (106). Also, SPMs target B cell epsilon germline transcript to selectively inhibit IgE without decreasing IgM and IgG or IgA production (107).

\section{SPM receptors and intracellular signaling}

To mediate cell type-specific actions, SPMs principally serve as ligands for select surface receptors. To date, four human SPM receptors are identified: ALX/FPR2, ERV1, DRV1, and DRV2. While named for the ligand used for identification (LXA, RvE1, RvD1, and RvD2, respectively), each receptor is capable of interacting with additional SPMs (30). RvD1, for example, interacts with ALX/FPR2 and DRV1 in a context-specific manner. In response to an inflammatory stimulus, neutrophils rapidly mobilize ALX/FPR2, but not DRV1, from secretory granules to cell membranes, so RvD1 interacts with DRV1 for homeostatic functions and with ALX/FPR2 for antineutrophil actions in resolving inflammation $(108,109)$. Notably, in some instances, SPMs display receptor-level antagonism at pro-phlogistic receptors. This antagonism is exemplified by inhibition of interactions of $\mathrm{LTB}_{4}$ with its receptor BLT1 by RvE1 and MaR1 $(110,111)$.

ALX/FPR2 receptors are broadly expressed and engaged by SPMs and peptides at distinct domains to influence intracellular signaling and cell functional responses. Interestingly, the acutephase protein serum amyloid A (SAA) can engage ALX/FPR2 receptors (112). When the counter-ligand is present in excess,
SAA and the SPM ligands allosterically inhibit each other to bias ALX/FPR2 signaling to promote either inflammation (SAA) or resolution (SPM) (113), suggesting a pivotal role for these receptors in the temporal course of an inflammatory response. ALX/FPR2 receptors can dimerize to alter ligand-dependent intracellular signaling (114). SAA interactions with ALX/FPR2 decrease formation of homodimers. In contrast, SPM engagement increases both ALX/FPR2 homodimerization and heterodimerization with FPR1 receptor. ALX/FPR2-FPR1 heterodimers have distinct downstream signaling events, with phosphorylation of the JNK/ caspase-3 pathway and proapoptotic signaling pathways.

$\mathrm{LXA}_{4}$ can also serve as an endogenous allosteric regulator of the endocannabinoid receptor CB1 (115). ERV1 receptors are also able to interact with both peptide and lipid ligands, chemerin and RvE1, respectively (32). As with ALX/FPR2, peptide and SPM signaling events by this receptor have distinct patterns of activation for intracellular pathways, including ERK and NF-кB phosphorylation (46). SPM interactions with ALX/FPR2 and ERV1 decrease $\mathrm{NF}-\kappa \mathrm{B}$ activity and cytokine production $(46,116)$. Translocation of $\mathrm{NF}-\kappa \mathrm{B}$ to the nucleus and its activity are also regulated by SPM signaling at DRV1 and DRV2 $(97,100,117)$. In another feed-forward mechanism for resolution, SPM receptor signaling by one mediator can promote expression of additional SPMs for other SPM receptors, exemplified by RvE1-ERV1 signaling promoting increased biosynthesis of $\mathrm{LXA}_{4}$ for ALX/FPR2-mediated resolution of allergic lung inflammation (118), and RvD2-DRV2 induction of RvD5 and PD1 for resolution of ischemia/reperfusion injury (37).

SPM receptor activation of intracellular signaling is cell typeand organ-specific; however, a few common themes emerge from existing results. Distinct ligand binding can influence receptor dimerization with alternate patterns of intracellular signal coupling to evoke specific phosphorylation cascades (114), polyisoprenyl phosphate remodeling (119), and microRNA expression patterns that together dictate cellular functional responses. Also, resolvin receptor activation signals specific microRNAs that carry sustained tissue responses (120-122).

\section{Neural systems and arthritic pain}

Human brain tissues produce RvD1, PD1, and MaR1 $(123,124)$. LXA 4 , MaR1, RvD1, NPD1, and PDX show neuroprotective activities. MaR1 and RvD1 downregulate $\beta$-amyloid-initiated inflammation with human microglia, suggesting a role for SPMs in neural tissues (123). MaR1 stimulates phagocytosis of the amyloid peptide $A_{\beta} 42$ (123), as does RvD1 (125) with lower SPM levels in Alzheimer's disease (126). MaR1 is neuroprotective in murine spinal cord injury, enabling functional recovery (127). DHA and NPD1 are neuroprotective in the retina (128), CNS, and brain (68), and PD1/NPD1 and resolvins may protect in early-stage Alzheimer's as well as in ischemic stroke $(124,129)$. Microglial cell production of proinflammatory cytokines is selectively reduced by SPMs (23, 24 ), with increased production of antiinflammatory IL-10 (130). In stress models, RvD1 and RvD2 prevent depression-like behaviors, and nanogram doses give sustained antidepressant effects $(131,132)$. Since it was first demonstrated that RvE1 and RvD1 are potent in resolving inflammatory and postoperative pain $(133,134)$ and that their receptors can regulate transient receptor potential (TRP) ion channels and spinal cord synaptic transmission, addi- 
tional resolvins (RvD2), protectins, and MaR1 (Figure 2) were shown to display potent ability to reduce inflammatory pain without altering motor functions or baseline pain $(33,135)$. RvE1 selectively blocks TRPV1 $\left(\mathrm{IC}_{50}=1 \mathrm{nM}\right), \operatorname{RvD} 1$ acts via TRPA1 $\left(\mathrm{IC}_{50}=9\right.$ $\mathrm{nM})$, and RvD2 acts via TRPV1 $\left(\mathrm{IC}_{50}=0.1 \mathrm{nM}\right)$ and TRPA1 $\left(\mathrm{IC}_{50}=\right.$ $2 \mathrm{nM}$ ) (136). RvE1 inhibits substance $P$ actions on peripheral nociceptive neurons (137). AT-RvD1 also mitigates motor and cognitive deficits in diffuse brain injury, and RvE1 increases posttraumatic sleep (138).

AT-RvD1 reduces osteoarthritic pain (139), as does precursor 17-HDHA (140), prompting validation of their receptors (ALX/ FPR2 and ERV/CMKLR1) in rat models of osteoarthritis pain (141). Plasma RvD2 levels correlate with reduction in astrogliosis in spinal cord (141). Fish consumption by humans, which increases plasma SPMs and precursors, reduces rheumatoid arthritis (RA) disease activity (142), and omega-3 fatty acid supplementation increases 18-HEPE and 17-HDHA, as well as RvEs, PD1, PDX, MaR1, and RvDs in plasma and synovial fluid (143). In synovial fluids, RvE2 increases are associated with reduced pain in arthritic patients (143). RvD1 and RvD3 are present in human arthritic synovial fluids $(144,145)$ and are protective in mouse arthritis, suggesting that increasing local joint SPMs may reduce RA pain. In human osteoarthritis pain, circulating 17-HDHA is associated with lower pain scores; however, circulating resolvins were below limits of detection (146). Vagal stimulation reduces arthritic joint inflammation in humans (147), and vagotomy in mice reduces pro-resolving mediators (i.e., SPMs, lipoxins, and netrin-1, an axonal guidance protein) that stimulate human monocytes to produce resolvins and lipoxins. The vagus nerve controls inflammation amplitude (147) by regulating SPMs and resolution (148). Acetylcholine from the vagus nerve induces $15-\mathrm{LOX}-1$ in type 3 innate lymphoid cells to produce protectins (i.e., PCTR1) that reduce infections (149). PCTRs and other new SPM sulfido-conjugates in tissue regeneration and their relation to leukotrienes were recently reviewed (15). Hence, plasticity of neural networks and their innate immune system interactions are regulated by specific SPMs.

\section{Fish to human resolvin, protectin, and maresin production}

SPMs can be produced in many human target organs (7). Availability of SPM synthetic standards, deuterium-labeled SPMs, and targeted LC-MS/MS (150) now permits identification of resolvins, protectins, and maresins in human tissues. In addition to substrates, trout brain (151) and salmon tissues contain resolvins (152), indicating that SPMs are conserved structures in evolution. In humans, SPMs are identified in several types of human specimens and biomatrices. PD1 is in exhaled breath condensates (61), RvE1 is in plasma (32), and RvD1 and RvD2 are in serum $(153,154)$. Lymph nodes, spleen, and serum possess most species of SPMs (150). Human spleen has RvD5, PD1, and MaR1, as well as RvE1, RvE2, RvE3, and $\mathrm{LXA}_{4}$; human axillary lymph nodes carry RvD1, RvD5, RvD6, RvE3, and lipoxins (150).

Mounting evidence indicates that SPM production is altered and often diminished in affected tissues and in circulation across a spectrum of chronic inflammatory diseases. In this context, in human synovial fluid from RA patients, RvD1, 17-epi-RvD1, RvD2, RvD3, RvE1, RvE2, RvE3, PD1, MaR1, 17-HDHA, and 18-HEPE are present (143-145), and RvD3 is reduced in serum from RA patients (144). RvD1 is sharply reduced in vulnerable regions of human atherosclerotic plaques (155), and, in omental adipose tissue from obese patients, RvDs, RvEs, PD1, MaR1, and lipoxins are reduced relative to $\mathrm{LTB}_{4}$ and prostaglandins (101). In brain and cerebrospinal fluid from Alzheimer's disease patients, RvD1 and LXA 4 are decreased $(123,126)$. Specific SPMs are present in human urine, namely RvD1, 17-epi-RvD1, and RvE2, which are decreased in smokers (156).

Recently, RvDs, PD1, and lipoxins were identified in human emotional tears with sex-specific levels that are reduced in females (40). RvDs are present in human skin blisters and increased in females (157). Healthy subjects' recovery phase from strenuous exercise is characterized by increases in serum RvD1, RvE1, LXA, and $\mathrm{LXB}_{4}$, which are blocked when subjects are pretreated with ibuprofen (93). In patients with chronic daily headaches, dietary omega-3 intervention increases plasma resolvins, 17-HDHA, and 18-HEPE with concomitant reduction in headache pain (158). In sepsis, plasma RvE1, RvD5, and 17-epi-PD1 increase in nonsurvivors relative to survivors and are potential biomarkers for critical illness (159). At birth, SPMs are present in human umbilical cord blood (RvE1, RvE2, RvE3, RvD1, 17-epi-RvD1, RvD2, 17-HDHA, and 18-HEPE) (160, 161), and placenta carries RvD1, 17-epi-RvD1, RvD2, PD1, 17-HDHA, and 18-HEPE (162). Prenatal n-3 supplementation increases 18-HEPE and 17-HDHA concentrations in human maternal and cord blood $(160,163)$, as well as in placenta (163), possibly supporting early immune functions (164). Along these lines, human breast milk contains bioactive SPM clusters consisting of RvD1, RvD2, RvD3, 17-epi-RvD3, RvD4, PD1, MaR1, RvE1, RvE2, RvE3, LXA LXB $_{4}, 17-\mathrm{HDHA}$, and 18-HEPE (165, $166)$, is a potential source of maternal-infant omega-3 and SPM transfer, and links to beneficial maternal n-3 supplementation during pregnancy with decreased incidence in children of asthma and respiratory infections (167), food allergy, and eczema (164).

Hence, specific SPMs and SPM clusters are present at biologically active amounts in human inflammatory exudates, physiologic tissues, and fluids as demonstrated by targeted LC-MS/ MS-based approaches. In human peripheral blood, several laboratories collectively identified plasma SPMs $(38,168)$, as well as a plasma SPM cluster consisting of RvE1, RvE2, RvD1, 17-epi-RvD1, RvD2, RvD5, RvD6, PD1, 17-HDHA, and 18-HEPE (150, 153), and a serum cluster of RvD1, 17-epi-RvD1, RvD2, RvD3, PD1, MaR1, RvE1, and RvE2. SPM concentrations attained in human peripheral blood target PMNs and monocytes (at the single-cell level determined by CyTOF mass cytometry) to increase phagocytosis and killing of E. coli (116). PUFAs are associated with reduced incidence of fatal coronary heart disease $(169,170)$, and it has recently been established that omega-3 supplementation at doses up to $10 \mathrm{~g} / \mathrm{d}$ (EPA and DHA) does not increase risk of bleeding or affect other coagulation parameters (75).

In human saliva, the leukotriene/RvD1 ratio predicts vascular disease (171), and saliva SPMs in aggressive periodontal disease may be useful for monitoring disease status (172). Randomized trials showed that alcohol consumption increases specific plasma SPMs: 18-HEPE, RvD1, and 17R-RvD1 (173). In obese women, $1.8 \mathrm{~g}$ daily EPA and DHA supplementation increased resolvins in plasma (174) and in lungs during acute respiratory distress syndrome (175). Thus, it appears that in certain organs, dietary n-3 
Table 2. SPM immunoresolvents in disease

$\begin{array}{lcc}\text { SPM } & \text { Disease model } & \text { Reference } \\ \text { RvE1 } & \text { Periodontal disease, dysbiosis } & 195 \\ & \text { Lung injury } & 46 \\ \text { RvE1 } & \text { Colitis } & 196 \\ & \text { Acid-induced lung injury } & 102 \\ \text { RvD5, PD1 } & \text { E. coli infection } & 37 \\ \text { RvD2 } & \text { Cecal ligation and puncture sepsis } & 53,117 \\ \text { RvD2 } & \text { Burn wound sepsis } & 197 \\ \text { RvD3 } & \text { Aging mice, peritonitis } & 86 \\ \text { RvD4 } & \text { Skin inflammation, peritonitis, organ } & 56,57 \\ & \text { protection } & 144,145 \\ \text { RvD1, RvD3 } & \text { Arthritis } & 189,190,198,199 \\ \text { RvE1, RvD1, and RvD2 } & \text { Cancer } & 193 \\ \text { RvE1 } & \text { Obesity } & 120 \\ \text { Lipoxins and resolvins } & \text { Neuroinflammation } & 185 \\ & \text { Postoperative cognitive decline } & 200 \\ & \text { Atherosclerosis } & 118\end{array}$

increases tissue SPMs, and that not all SPMs (Figure 2) are produced in each organ, save resolving exudates. Also, some human tissues and fluids, e.g., breast milk, placenta, lymph nodes, lung, and tears, may constitutively biosynthesize SPMs, while others, such as blood (116) and spleen (176), produce SPMs upon cell activation. Now that these procedures are available, additional human studies are needed to investigate the role of organ-specific SPM production and actions in human tissues.

\section{Novel therapeutics: SPM inactivation and metabolically stable mimetics}

While some resolvins and other SPMs reach circulation $(150,159)$, most are metabolically inactivated at local sites of inflammation (168). For example, RvE1 is converted via an eicosanoid oxidoreductase (EOR, specifically prostaglandin dehydrogenase) (177) to inactive 18-oxo-RvE1. Stable analogs of RvE1 that prevent dehydrogenation at carbon-18 are longer-acting, demonstrating potent mimetic actions of RvE1 in pain and inflammation $(134,168)$. RvD1 is also subject to dehydrogenation via EOR at carbon-17 alcohol to inactive 17-oxo-RvD1 (35). Stable RvD1 analogs that prevent rapid dehydrogenation at carbon-17 are potent mimetics (54). RvD4, RvD5, and MaR1 are also subject to local metabolism to oxo-products $(37,56,111)$. Nanomedicines were designed that deliver SPMs and their analogs (72) and with unidirectional sustained delivery (178). A benzo-RvD1 analog was designed to retain RvD1's pro-resolving actions, requiring fewer steps in organic synthesis by eliminating the tetraene conjugation, which is less potent
(179). An RvE1 analog was successful in human clinical trial for dry eye inflammation $(180,181)$, and another pro-resolving stable SPM analog is currently in trial for periodontal inflammation (182). Several of these molecules are in clinical development programs. Given the number of SPMs and their potencies in multiple organs, investigation of mimetics and/or metabolically stable analogs of SPMs (Figure 2) could reveal their potential in promoting resolution of pathologic inflammation, addressing resolution defects that are present in many human diseases.

\section{Therapeutic opportunities for SPM mechanisms}

SPMs have proven potent pro-resolving actions in a range of disease models (Table 2); given their potency, many drug development opportunities are possible. Human PMN swarming activates a temporal biosynthetic code that produces stop signals, e.g., LXA 4 and resolvins, at critical PMN densities (183). Temporal biosynthesis with lipid mediator class switching is documented in human blisters (157) and with specific drugs (184) (e.g., dexmedetomidine) that can prevent cognitive decline by activating SPMs (185). In randomized trials, immunonutrition (dietary interventions that modulate the immune system) increases RvE1 in patients undergoing hepatobiliary surgery, giving lower rates of infection complications and severity (186). Treating coronary artery disease patients with Lovaza resurrects SPM production (187). Enhancing SPMs via substrate supplementation may also improve outcomes in military personnel and in traumatic brain injury (188). Building on the ability of SPMs to clear debris, resolving cancer inflammation with RvE1, RvD1, or RvD2 reduces chemotherapyinitiated tumor debris and lowers dose requirements for cancer drugs (189) by stimulating resolution macrophages (190). Western diet triggers inflammasome-mediated trained immunity with heightened inflammation (191). RvT and lipoxin reduce inflammasome activation $(26,192)$, suggesting that SPMs can help control obesity (193) and other diseases in which inflammation is excessive (Table 2). The recent identification of a third phase of acute inflammation that arcs into adaptive immunity (16) supplies new targets and opportunities. In addition to innate immunity, RvD1, RvD2, and RvE1 target T and B lymphocytes $(105,107)$, widening the scope and potential for SPM-based therapeutics and resolution physiology/pharmacology.

\section{Acknowledgments}

We thank Mary Halm Small for expert assistance in manuscript preparation, and acknowledge support from NIH grant P01GM095467 (to CNS and BDL).

Address correspondence to: Charles N. Serhan, Center for Experimental Therapeutics and Reperfusion Injury, 60 Fenwood Road BTM 3-016, Boston, Massachusetts 02115, USA. Phone: 617.525.5001; Email: cserhan@bwh.harvard.edu.
1. Myers GL, et al. CDC/AHA Workshop on Markers of Inflammation and Cardiovascular Disease: Application to Clinical and Public Health Practice: report from the laboratory science discussion group. Circulation. 2004;110(25):e545-e549.

2. Calder PC. Marine omega-3 fatty acids and inflammatory processes: effects, mechanisms and clinical relevance. Biochim Biophys Acta. 2015;1851(4):469-484.

3. Calder PC. Omega-3 fatty acids and inflammatory processes: from molecules to man. Biochem Soc Trans. 2017;45(5):1105-1115.
4. Cotran RS, Kumar V, Collins T, eds. Robbins Pathologic Basis of Disease. Philadelphia, Pennsylvania, USA: W.B. Saunders Co.; 1999.

5. Malawista SE, de Boisfleury Chevance A, van Damme J, Serhan CN. Tonic inhibition of chemotaxis in human plasma. Proc Natl Acad Sci US A. 
2008;105(46):17949-17954.

6. Gordon S. Phagocytosis: an immunobiologic process. Immunity. 2016;44(3):463-475.

7. Serhan CN. Pro-resolving lipid mediators are leads for resolution physiology. Nature. 2014;510(7503):92-101.

8. Ward PA. Acute and chronic inflammation. In: Serhan CN, Ward PA, Gilroy DW, eds. Fundamentals of Inflammation. New York, New York, USA: Cambridge University Press; 2010:1-16.

9. Serhan CN, Clish CB, Brannon J, Colgan SP, Chiang N, Gronert K. Novel functional sets of lipid-derived mediators with antiinflammatory actions generated from omega-3 fatty acids via cyclooxygenase 2-nonsteroidal antiinflammatory drugs and transcellular processing. JExp Med. 2000;192(8):1197-1204.

10. Takano T, Clish CB, Gronert K, Petasis N, Serhan $\mathrm{CN}$. Neutrophil-mediated changes in vascular permeability are inhibited by topical application of aspirin-triggered 15-epi-lipoxin A4 and novel lipoxin B4 stable analogues. JClin Invest. 1998;101(4):819-826.

11. Levy BD, Clish CB, Schmidt B, Gronert K, Serhan $\mathrm{CN}$. Lipid mediator class switching during acute inflammation: signals in resolution. Nat Immunol. 2001;2(7):612-619.

12. Bandeira-Melo C, et al. Cyclooxygenase-2derived prostaglandin $\mathrm{E} 2$ and lipoxin $\mathrm{A} 4$ accelerate resolution of allergic edema in Angiostrongylus costaricensis-infected rats: relationship with concurrent eosinophilia. JImmunol. 2000;164(2):1029-1036.

13. Vane JR, Botting RM, eds. Therapeutic Roles of Selective COX-2 Inhibitors. London, United Kingdom: William Harvey Press; 2001.

14. Dalli J, et al. Resolvin D3 and aspirin-triggered resolvin D3 are potent immunoresolvents. Chem Biol. 2013;20(2):188-201.

15. Serhan CN, Chiang N, Dalli J. New pro-resolving $\mathrm{n}-3$ mediators bridge resolution of infectious inflammation to tissue regeneration [published online ahead of print September 1, 2017]. Mol Aspects Med.https://doi.org/10.1016/ j.mam.2017.08.002.

16. Fullerton JN, Gilroy DW. Resolution of inflammation: a new therapeutic frontier. Nat Rev Drug Discov. 2016;15(8):551-567.

17. Perretti M. The resolution of inflammation: new mechanisms in patho-physiology open opportunities for pharmacology. Semin Immunol. 2015;27(3):145-148.

18. Godson C, Mitchell S, Harvey K, Petasis NA, Hogg N, Brady HR. Cutting edge: lipoxins rapidly stimulate nonphlogistic phagocytosis of apoptotic neutrophils by monocyte-derived macrophages. J Immunol. 2000;164(4):1663-1667.

19. Serhan CN. Lipoxins and novel aspirin-triggered 15-epi-lipoxins (ATL): a jungle of cell-cell interactions or a therapeutic opportunity? Prostaglandins. 1997;53(2):107-137.

20. Serhan CN, et al. Resolution of inflammation: state of the art, definitions and terms. FASEB J. 2007;21(2):325-332.

21. Samuelsson B, Dahlén SE, Lindgren JA, Rouzer $\mathrm{CA}$, Serhan CN. Leukotrienes and lipoxins: structures, biosynthesis, and biological effects. Science. 1987;237(4819):1171-1176.
22. Bannenberg GL, et al. Molecular circuits of resolution: formation and actions of resolvins and protectins. J Immunol. 2005;174(7):4345-4355.

23. Serhan CN, et al. Resolvins: a family of bioactive products of omega-3 fatty acid transformation circuits initiated by aspirin treatment that counter pro-inflammation signals. J Exp Med. 2002;196(8):1025-1037.

24. Hong S, Gronert K, Devchand PR, Moussignac RL, Serhan CN. Novel docosatrienes and 17Sresolvins generated from docosahexaenoic acid in murine brain, human blood, and glial cells. Autacoids in anti-inflammation. J Biol Chem. 2003;278(17):14677-14687.

25. Serhan CN, et al. Maresins: novel macrophage mediators with potent anti-inflammatory and pro-resolving actions. J Exp Med. 2009;206(1):15-23.

26. Dalli J, Chiang N, Serhan CN. Elucidation of novel 13-series resolvins that increase with atorvastatin and clear infections. Nat Med. 2015;21(9):1071-1075.

27. Dalli J, Colas RA, Serhan CN. Novel n-3 immunoresolvents: structures and actions. Sci Rep. 2013;3:1940.

28. Gilroy DW. The role of aspirin-triggered lipoxins in the mechanism of action of aspirin. Prostaglandins Leukot Essent Fatty Acids. 2005;73(3-4):203-210.

29. Serhan $C N$. Treating inflammation and infection in the 21st century: new hints from decoding resolution mediators and mechanisms. FASEB J. 2017;31(4):1273-1288.

30. Chiang N, Serhan CN. Structural elucidation and physiologic functions of specialized pro-resolving mediators and their receptors. Mol Aspects Med. 2017;58:114-129.

31. Serhan CN, et al. Novel proresolving aspirintriggered DHA pathway. Chem Biol. 2011;18(8):976-987.

32. Arita M, et al. Stereochemical assignment, anti-inflammatory properties, and receptor for the omega-3 lipid mediator resolvin E1. J Exp Med. 2005;201(5):713-722.

33. Serhan $\mathrm{CN}$, et al. Macrophage proresolving mediator maresin 1 stimulates tissue regeneration and controls pain. FASEB J. 2012;26(4):1755-1765.

34. Serhan CN, et al. Anti-inflammatory actions of neuroprotectin D1/protectin D1 and its natural stereoisomers: assignments of dihydroxy-containing docosatrienes. JImmunol. 2006;176(3):1848-1859.

35. Sun YP, et al. Resolvin D1 and its aspirin-triggered 17R epimer. Stereochemical assignments, antiinflammatory properties, and enzymatic inactivation. J Biol Chem. 2007;282(13):9323-9334.

36. Hansen TV, Dalli J, Serhan CN. The novel lipid mediator PD1n-3 DPA: an overview of the structural elucidation, synthesis, biosynthesis and bioactions. Prostaglandins Other Lipid Mediat . 2017;133:103-110.

37. Chiang $\mathrm{N}$, et al. Infection regulates pro-resolving mediators that lower antibiotic requirements. Nature. 2012;484(7395):524-528.

38. Oh SF, Pillai PS, Recchiuti A, Yang R, Serhan CN. Pro-resolving actions and stereoselective biosynthesis of $18 \mathrm{~S}$ E-series resolvins in human leukocytes and murine inflammation. J Clin Invest. 2011;121(2):569-581.
39. Serhan CN, Petasis NA. Resolvins and protectins in inflammation-resolution. Chem Rev. 2011;111(10):5922-5943.

40. English JT, Norris PC, Hodges RR, Dartt DA, Serhan CN. Identification and profiling of specialized pro-resolving mediators in human tears by lipid mediator metabolomics. Prostaglandins Leukot Essent Fatty Acids. 2017;117:17-27.

41. Tungen JE, Aursnes M, Dalli J, Arnardottir H, Serhan CN, Hansen TV. Total synthesis of the anti-inflammatory and pro-resolving lipid mediator MaR1n-3 DPA utilizing an sp(3) -sp(3) Negishi cross-coupling reaction. Chemistry. 2014;20(45):14575-14578.

42. Rodriguez AR, Spur BW. Total synthesis of the macrophage derived anti-inflammatory lipid mediator Maresin 1. Tetrahedron Lett. 2012;53(32):4169-4172.

43. Rodriguez AR, Spur BW. Total synthesis of the anti-inflammatory lipid mediator Resolvin E2. Tetrahedron Lett. 2012;53:1912-1915.

44. Dona M, et al. Resolvin E1, an EPA-derived mediator in whole blood, selectively counterregulates leukocytes and platelets. Blood. 2008;112(3):848-855.

45. Fredman G, Serhan CN. Specialized proresolving mediator targets for RvE1 and RvD1 in peripheral blood and mechanisms of resolution. Biochem J. 2011;437(2):185-197.

46. El Kebir D, Gjorstrup P, Filep JG. Resolvin E1 promotes phagocytosis-induced neutrophil apoptosis and accelerates resolution of pulmonary inflammation. Proc Natl Acad Sci U S A. 2012;109(37):14983-14988.

47. Tjonahen E, et al. Resolvin E2: identification and anti-inflammatory actions: pivotal role of human 5-lipoxygenase in resolvin $\mathrm{E}$ series biosynthesis. Chem Biol. 2006;13(11):1193-1202.

48. Endo J, et al. 18-HEPE, an n-3 fatty acid metabolite released by macrophages, prevents pressure overload-induced maladaptive cardiac remodeling. J Exp Med. 2014;211(8):1673-1687.

49. Isobe $Y$, et al. Identification and structure determination of novel anti-inflammatory mediator resolvin E3, 17,18-dihydroxyeicosapentaenoic acid. J Biol Chem. 2012;287(13):10525-10534.

50. Sawada Y, et al. Resolvin E1 inhibits dendritic cell migration in the skin and attenuates contact hypersensitivity responses. J Exp Med. 2015;212(11):1921-1930.

51. Oh SF, Dona M, Fredman G, Krishnamoorthy S, Irimia D, Serhan CN. Resolvin E2 formation and impact in inflammation resolution. JImmunol. 2012;188(9):4527-4534.

52. Dalli J, Serhan CN. Specific lipid mediator signatures of human phagocytes: microparticles stimulate macrophage efferocytosis and pro-resolving mediators. Blood. 2012;120(15):e60-e72.

53. Spite M, et al. Resolvin D2 is a potent regulator of leukocytes and controls microbial sepsis. Nature. 2009;461(7268):1287-1291.

54. Kasuga K, et al. Rapid appearance of resolvin precursors in inflammatory exudates: novel mechanisms in resolution. J Immunol. 2008;181(12):8677-8687.

55. Norris PC, Arnardottir H, Sanger JM, Fichtner D, Keyes GS, Serhan CN. Resolvin D3 multilevel proresolving actions are host protective during infection [published online ahead of print 
January 22, 2016]. Prostaglandins Leukot Essent Fatty Acids. https://doi.org/10.1016/ j.plefa.2016.01.001.

56. Winkler JW, et al. Structural insights into Resolvin D4 actions and further metabolites via a new total organic synthesis and validation [published online ahead of print January 29, 2018]. J Leukoc Biol. https://doi.org/10.1002/JLB.3MI0617-254R.

57. Winkler JW, et al. Resolvin D4 stereoassignment and its novel actions in host protection and bacterial clearance. Sci Rep. 2016;6:18972.

58. Serhan CN, Dalli J, Colas RA, Winkler JW, Chiang N. Protectins and maresins: new pro-resolving families of mediators in acute inflammation and resolution bioactive metabolome. Biochim Biophys Acta. 2015;1851(4):397-413.

59. Katakura M, et al. Chronic arachidonic acid administration decreases docosahexaenoic acid-and eicosapentaenoic acid-derived metabolites in kidneys of aged rats. PLoS One. 2015;10(10):e0140884.

60. Yamada T, Tani Y, Nakanishi H, Taguchi R, Arita $\mathrm{M}$, Arai H. Eosinophils promote resolution of acute periotonitis by producing proresolving mediators in mice. FASEB J. 2011;25(2):561-568.

61. Levy BD, et al. Protectin D1 is generated in asthma and dampens airway inflammation and hyper-responsiveness. J Immunol. 2007;178(1):496-502.

62. Miyata J, et al. Dysregulated synthesis of protectin D1 in eosinophils from patients with severe asthma. JAllergy Clin Immunol. 2013;131(2):353-60.e1.

63. Masterson JC, et al. Eosinophil-mediated signalling attenuates inflammatory responses in experimental colitis. Gut. 2015;64(8):1236-1247.

64. White PJ, et al. Transgenic $\omega-3$ PUFA enrichment alters morphology and gene expression profile in adipose tissue of obese mice: potential role for protectins. Metab Clin Exp. 2015;64(6):666-676.

65. Fonseca FC, Orlando RM, Turchetti-Maia RM, de Francischi JN. Comparative effects of the $\omega 3$ polyunsaturated fatty acid derivatives resolvins E1 and D1 and protectin DX in models of inflammation and pain. J Inflamm Res. 2017;10:119-133.

66. Stein K, et al. A role for 12/15-lipoxygenase-derived proresolving mediators in postoperative ileus: protectin DX-regulated neutrophil extravasation. J Leukoc Biol. 2016;99(2):231-239.

67. Bazan NG, Calandria JM, Serhan CN. Rescue and repair during photoreceptor cell renewal mediated by docosahexaenoic acid-derived neuroprotectin D1. J Lipid Res. 2010;51(8):2018-2031.

68. Asatryan A, Bazan NG. Molecular mechanisms of signaling via the docosanoid neuroprotectin D1 for cellular homeostasis and neuroprotection. J Biol Chem. 2017;292(30):12390-12397.

69. Deng B, et al. Maresin biosynthesis and identification of maresin 2, a new anti-inflammatory and pro-resolving mediator from human macrophages. PLoS One. 2014;9(7):e102362.

70. Dalli J, et al. The novel 13S,14S-epoxy-maresin is converted by human macrophages to maresin1 (MaR1), inhibits leukotriene A4 hydrolase (LTA4H), and shifts macrophage phenotype. FASEB J. 2013;27(7):2573-2583.

71. Murakami M, Sato H, Miki Y, Yamamoto K, Taketomi Y. A new era of secreted phospholipase $\mathrm{A}_{2}$. JLipid Res. 2015;56(7):1248-1261.
72. Norling LV, Spite M, Yang R, Flower RJ, Perretti $\mathrm{M}$, Serhan $\mathrm{CN}$. Cutting edge: Humanized nano-proresolving medicines mimic inflammation-resolution and enhance wound healing. JImmunol. 2011;186(10):5543-5547.

73. Yates CM, Calder PC, Ed Rainger G. Pharmacology and therapeutics of omega-3 polyunsaturated fatty acids in chronic inflammatory disease. Pharmacol Ther. 2014;141(3):272-282.

74. Peltomaa E, Johnson MD, Taipale SJ. Marine cryptophytes are great sources of EPA and DHA. Mar Drugs. 2017;16(1):E3.

75. Jeansen S, Witkamp RF, Garthoff JA, van Helvoort A, Calder PC. Fish oil LC-PUFAs do not affect blood coagulation parameters and bleeding manifestations: analysis of 8 clinical studies with selected patient groups on omega-3enriched medical nutrition. Clin Nutr. 2018;37(30):948-957.

76. Chen CT, et al. Plasma non-esterified docosahexaenoic acid is the major pool supplying the brain. Sci Rep. 2015;5:15791.

77. Burdge GC, Jones AE, Wootton SA. Eicosapentaenoic and docosapentaenoic acids are the principal products of alpha-linolenic acid metabolism in young men. Br J Nutr. 2002;88(4):355-363.

78. Markworth JF, et al. Divergent shifts in lipid mediator profile following supplementation with n-3 docosapentaenoic acid and eicosapentaenoic acid. FASEB J. 2016;30(11):3714-3725.

79. Vik A, Dalli J, Hansen TV. Recent advances in the chemistry and biology of anti-inflammatory and specialized pro-resolving mediators biosynthesized from n-3 docosapentaenoic acid. Bioorg Med Chem Lett. 2017;27(11):2259-2266.

80. Gobbetti T, et al. Protectin D1n-3 DPAand resolvin D5n-3 DPAare effectors of intestinal protection. Proc Natl Acad Sci U S A. 2017;114(15):3963-3968.

81. Serhan CN. Lipoxins and aspirin-triggered 15-epi-lipoxins are the first lipid mediators of endogenous anti-inflammation and resolution. Prostaglandins Leukot Essent Fatty Acids. 2005;73(3-4):141-162.

82. Lee CR, Zeldin DC. Resolvin infectious inflammation by targeting the host response. $N$ Engl J Med. 2015;373(22):2183-2185.

83. Tsuda S, et al. Novel mechanism of regulation of the 5-lipoxygenase/leukotriene B4pathway by high-density lipoprotein in macrophages. Sci Rep. 2017;7(1):12989.

84. Serhan CN, Savill J. Resolution of inflammation: the beginning programs the end. Nat Immunol. 2005;6(12):1191-1197.

85. Schwab JM, Chiang N, Arita M, Serhan CN. Resolvin E1 and protectin D1 activate inflammation-resolution programmes. Nature. 2007;447(7146):869-874.

86. Arnardottir HH, Dalli J, Colas RA, Shinohara $\mathrm{M}$, Serhan CN. Aging delays resolution of acute inflammation in mice: reprogramming the host response with novel nano-proresolving medicines. JImmunol. 2014;193(8):4235-4244.

87. Luo B, et al. Phagocyte respiratory burst activates macrophage erythropoietin signalling to promote acute inflammation resolution. Nat Commun. 2016;7:12177.

88. Sugimoto MA, et al. Plasmin and plasminogen induce macrophage reprogramming and regulate key steps of inflammation resolution via annexin A1. Blood.2017;129(21):2896-2907.

89. Chiang $\mathrm{N}$, et al. Inhaled carbon monoxide accelerates resolution of inflammation via unique pro-resolving mediator heme oxygenase-1 circuits. J Immunol. 2013;190(12):6378-6388.

90. Rossi AG, et al. Cyclin-dependent kinase inhibitors enhance the resolution of inflammation by promoting inflammatory cell apoptosis. Nat Med. 2006;12(9):1056-1064.

91. Perretti M, et al. Endogenous lipid- and peptide-derived anti-inflammatory pathways generated with glucocorticoid and aspirin treatment activate the lipoxin A4 receptor. Nat Med. 2002;8(11):1296-1302.

92. Gilroy DW, Colville-Nash PR, Willis D, Chivers J, Paul-Clark MJ, Willoughby DA. Inducible cycloxygenase may have anti-inflammatory properties. Nat Med.1999;5(6):698-701.

93. Markworth JF, et al. Human inflammatory and resolving lipid mediator responses to resistance exercise and ibuprofen treatment. Am J Physiol Regul Integr Comp Physiol. 2013;305(11):R1281-R1296.

94. Chiang N, Schwab JM, Fredman G, Kasuga K, Gelman S, Serhan CN. Anesthetics impact the resolution of inflammation. PLoS One. 2008;3(4):e1879.

95. Perretti M, Leroy X, Bland EJ, Montero-Melendez T. Resolution pharmacology: opportunities for therapeutic innovation in inflammation. Trends Pharmacol Sci. 2015;36(11):737-755.

96. Abdulnour RE, et al. Aspirin-triggered resolvin D1 is produced during self-resolving gram-negative bacterial pneumonia and regulates host immune responses for the resolution of lung inflammation. Mucosal Immunol. 2016;9(5):1278-1287.

97. Chiang N, Dalli J, Colas RA, Serhan CN. Identification of resolvin D2 receptor mediating resolution of infections and organ protection. J Exp Med. 2015;212(8):1203-1217.

98. Abdulnour RE, et al. Maresin 1 biosynthesis during platelet-neutrophil interactions is organ-protective. Proc Natl Acad Sci U S A. 2014;111(46):16526-16531.

99. Colby JK, et al. Resolvin D3 and aspirin-triggered resolvin D3 are protective for injured epithelia. Am J Pathol. 2016;186(7):1801-1813.

100.Eickmeier O, et al. Aspirin-triggered resolvin D1 reduces mucosal inflammation and promotes resolution in a murine model of acute lung injury. Mucosal Immunol. 2013;6(2):256-266.

101. Titos E, et al. Signaling and immunoresolving actions of resolvin D1 in inflamed human visceral adipose tissue. JImmunol. 2016;197(8):3360-3370.

102. Levy BD, Serhan CN. Resolution of acute inflammation in the lung. Annu Rev Physiol. 2014;76:467-492.

103. Barnig C, et al. Lipoxin A4 regulates natural killer cell and type 2 innate lymphoid cell activation in asthma. Sci Transl Med. 2013;5(174):174ra26.

104. Krishnamoorthy N, et al. Cutting edge: maresin-1 engages regulatory $\mathrm{T}$ cells to limit type 2 innate lymphoid cell activation and promote resolution of lung inflammation. JImmunol. 2015;194(3):863-867.

105. Chiurchiù V, et al. Proresolving lipid mediators 
resolvin D1, resolvin D2, and maresin 1 are critical in modulating $\mathrm{T}$ cell responses. Sci Transl Med. 2016;8(353):353ra111.

106. Ramon S, Gao F, Serhan CN, Phipps RP. Specialized proresolving mediators enhance human $\mathrm{B}$ cell differentiation to antibody-secreting cells. JImmunol. 2012;189(2):1036-1042.

107. Kim N, Ramon S, Thatcher TH, Woeller CF, Sime PJ, Phipps RP. Specialized proresolving mediators (SPMs) inhibit human B-cell IgE production. Eur J Immunol. 2016;46(1):81-91.

108. Krishnamoorthy S, et al. Resolvin D1 binds human phagocytes with evidence for pro-resolving receptors. Proc Natl Acad Sci U S A. 2010;107(4):1660-1665.

109. Norling LV, Dalli J, Flower RJ, Serhan CN, Perretti M. Resolvin D1 limits polymorphonuclear leukocytes recruitment to inflammatory loci: receptor dependent actions. Arterioscler Thromb Vasc Biol. 2012;32(8):1970-1978.

110. Arita M, Ohira T, Sun YP, Elangovan S, Chiang $\mathrm{N}$, Serhan CN. Resolvin E1 selectively interacts with leukotriene B4 receptor BLT1 and ChemR23 to regulate inflammation. J Immunol. 2007;178(6):3912-3917.

111. Colas RA, et al. Identification and actions of the maresin 1 metabolome in infectious inflammation. J Immunol. 2016;197(11):4444-4452.

112. He R, Sang H, Ye RD. Serum amyloid A induces IL-8 secretion through a $G$ protein-coupled receptor, FPRL1/LXA4R. Blood. 2003;101(4):1572-1581.

113. Bozinovski S, et al. Serum amyloid A opposes lipoxin A(4) to mediate glucocorticoid refractory lung inflammation in chronic obstructive pulmonary disease. Proc Natl Acad Sci U S A. 2012;109(3):935-940.

114. $\mathrm{m}$. Ligand-specific conformational change of the G-protein-coupled receptor ALX/FPR2 determines proresolving functional responses. Proc Natl Acad Sci U S A. 2013;110(45):18232-18237.

115. Pamplona FA, et al. Anti-inflammatory lipoxin A4 is an endogenous allosteric enhancer of CB1 cannabinoid receptor. Proc Natl Acad Sci U S A. 2012;109(51):21134-21139.

116. Norris PC, Libreros S, Chiang N, Serhan CN. A cluster of immunoresolvents links coagulation to innate host defense in human blood. Sci Signal. 2017;10(490):eaan1471.

117. Chiang N, de la Rosa X, Libreros S, Serhan CN. Novel resolvin D2 receptor axis in infectious inflammation. J Immunol. 2017;198(2):842-851.

118. Haworth O, Cernadas M, Yang R, Serhan CN, Levy BD. Resolvin E1 regulates interleukin 23, interferon-gamma and lipoxin A4 to promote the resolution of allergic airway inflammation. Nat Immunol. 2008;9(8):873-879.

119. Carlo T, Kalwa H, Levy BD. 15-Epi-lipoxin A4 inhibits human neutrophil superoxide anion generation by regulating polyisoprenyl diphosphate phosphatase 1. FASEB J. 2013;27(7):2733-2741.

120. Bisicchia E, et al. Resolvin D1 halts remote neuroinflammation and improves functional recovery after focal brain damage via ALX/FPR2 receptor-regulated microRNAs [published online ahead of print January 22, 2018]. Mol Neurobiol. https://doi.org/10.1007/s12035-018-0889-z.

121. Fredman G, Li Y, Dalli J, Chiang N, Serhan CN.
Self-limited versus delayed resolution of acute inflammation: temporal regulation of pro-resolving mediators and microRNA. Sci Rep. 2012;2:639.

122. Recchiuti $A$, et al. Immunoresolving actions of oral resolvin D1 include selective regulation of the transcription machinery in resolution-phase mouse macrophages. FASEB J. 2014;28(7):3090-3102.

123. Zhu M, et al. Pro-resolving lipid mediators improve neuronal survival and increase $A \beta 42$ phagocytosis. Mol Neurobiol. 2016;53(4):2733-2749.

124. Nielsen MM, et al. Mass spectrometry imaging of biomarker lipids for phagocytosis and signalling during focal cerebral ischaemia. Sci Rep. 2016;6:39571.

125. Fiala M, Terrando N, Dalli J. Specialized proresolving mediators from omega-3 fatty acids improve amyloid- $\beta$ phagocytosis and regulate inflammation in patients with minor cognitive impairment. JAlzheimers Dis. 2015;48(2):293-301.

126. Wang $X$, et al. Resolution of inflammation is altered in Alzheimer's disease. Alzheimers Dement. 2015;11(1):40-50.e42.

127. Francos-Quijorna I, et al. Maresin 1 promotes inflammatory resolution, neuroprotection, and functional neurological recovery after spinal cord injury. J Neurosci. 2017;37(48):11731-11743.

128. Mukherjee PK, Marcheselli VL, Serhan CN, Bazan NG. Neuroprotectin D1: a docosahexaenoic acid-derived docosatriene protects human retinal pigment epithelial cells from oxidative stress. Proc Natl Acad Sci U S A. 2004;101(22):8491-8496.

129. Belayev L, et al. Neuroprotectin D1 upregulates Iduna expression and provides protection in cellular uncompensated oxidative stress and in experimental ischemic stroke. Cell Death Differ. 2017;24(6):1091-1099.

130. Rajasagi NK, Bhela S, Varanasi SK, Rouse BT. Frontline Science: Aspirin-triggered resolvin D1 controls herpes simplex virus-induced corneal immunopathology. J Leukoc Biol. 2017;102(5):1159-1171.

131. Deyama S, et al. Resolvin D1 and D2 reverse lipopolysaccharide-induced depression-like behaviors through the mTORC1 signaling pathway. Int J Neuropsychopharmacol. 2017;20(7):575-584.

132. Ishikawa Y, et al. Rapid and sustained antidepressant effects of resolvin D1 and D2 in a chronic unpredictable stress model. Behav Brain Res. 2017;332:233-236.

133. Ji RR, Xu ZZ, Strichartz G, Serhan CN. Emerging roles of resolvins in the resolution of inflammation and pain. Trends Neurosci. 2011;34(11):599-609.

134. Xu ZZ, et al. Resolvins RvE1 and RvD1 attenuate inflammatory pain via central and peripheral actions. Nat Med. 2010;16(5):592-597.

135. Park CK, Xu ZZ, Liu T, Lü N, Serhan CN, Ji RR. Resolvin D2 is a potent endogenous inhibitor for transient receptor potential subtype V1/A1, inflammatory pain, and spinal cord synaptic plasticity in mice: distinct roles of resolvin D1, D2, and E1. J Neurosci. 2011;31(50):18433-18438.

136. Park CK, Lü N, Xu ZZ, Liu T, Serhan CN, Ji RR. Resolving TRPV1 and TNF- $\alpha$-mediated spinal cord synaptic plasticity and inflammatory pain with neuroprotectin D1. J Neurosci. 2011;31(42):15072-15085

137. Jo YY, Lee JY, Park CK. Resolvin E1 inhibits substance P-induced potentiation of TRPV1 in primary sensory neurons. Mediators Inflamm. 2016;2016:5259321.

138. Harrison JL, et al. Resolvins AT-D1 and E1 differentially impact functional outcome, posttraumatic sleep, and microglial activation following diffuse brain injury in the mouse. Brain Behav Immun. 2015;47:131-140.

139. Meesawatsom P, Burston J, Hathway G, Bennett A, Chapman V. Inhibitory effects of aspirin-triggered resolvin D1 on spinal nociceptive processing in rat pain models. J Neuroinflammation. 2016;13(1):233

140.Lima-Garcia JF, Dutra RC, da Silva K, Motta EM, Campos MM, Calixto JB. The precursor of resolvin $\mathrm{D}$ series and aspirin-triggered resolvin D1 display anti-hyperalgesic properties in adjuvant-induced arthritis in rats. Br J Pharmacol. 2011;164(2):278-293.

141. Huang J, et al. Targeting the D-series resolvin receptor system for the treatment of osteoarthritic pain. Arthritis Rheumatol. 2017;69(5):996-1008.

142. Tedeschi SK, Bathon JM, Giles JT, Lin TC, Yoshida K, Solomon DH. Relationship between fish consumption and disease activity in rheumatoid arthritis. Arthritis Care Res (Hoboken). 2018;70(3):327-332.

143. Barden AE, Moghaddami M, Mas E, Phillips M, Cleland LG, Mori TA. Specialised pro-resolving mediators of inflammation in inflammatory arthritis. Prostaglandins Leukot Essent Fatty Acids. 2016;107:24-29.

144.Arnardottir HH, Dalli J, Norling LV, Colas RA, Perretti M, Serhan CN. Resolvin D3 is dysregulated in arthritis and reduces arthritic inflammation. J Immunol. 2016;197(6):2362-2368.

145. Norling LV, et al. Proresolving and cartilage-protective actions of resolvin D1 in inflammatory arthritis. JCI Insight. 2016;1(5):e85922.

146.Valdes AM, et al. Association of the resolvin precursor 17-HDHA, but not D- or E- series resolvins, with heat pain sensitivity and osteoarthritis pain in humans. Sci Rep. 2017;7(1):10748.

147. Koopman FA, et al. Vagus nerve stimulation inhibits cytokine production and attenuates disease severity in rheumatoid arthritis. Proc Natl Acad Sci U S A. 2016;113(29):8284-8289.

148. Mirakaj V, Dalli J, Granja T, Rosenberger P, Serhan CN. Vagus nerve controls resolution and pro-resolving mediators of inflammation. J Exp Med. 2014;211(6):1037-1048.

149.Dalli J, Colas RA, Arnardottir H, Serhan CN. Vagal regulation of group 3 innate lymphoid cells and the immunoresolvent PCTR1 controls infection resolution. Immunity. 2017;46(1):92-105.

150. Colas RA, Shinohara M, Dalli J, Chiang N, Serhan $\mathrm{CN}$. Identification and signature profiles for pro-resolving and inflammatory lipid mediators in human tissue. Am J Physiol Cell Physiol. 2014;307(1):C39-C54.

151. Hong S, Tjonahen E, Morgan EL, Lu Y, Serhan CN, Rowley AF. Rainbow trout (Oncorhynchus mykiss) brain cells biosynthesize novel docosahexaenoic acid-derived resolvins and protectins-mediator lipidomic analysis. Prostaglandins Other Lipid Mediat. 2005;78(1-4):107-116.

152. Raatz SK, et al. Baking reduces prostaglandin, resolvin, and hydroxy-fatty acid content of farm- 
raised Atlantic salmon (Salmo salar). J Agric Food Chem. 2011;59(20):11278-11286.

153. Mas E, Croft KD, Zahra P, Barden A, Mori TA. Resolvins D1, D2, and other mediators of self-limited resolution of inflammation in human blood following n-3 fatty acid supplementation. Clin Chem. 2012;58(10):1476-1484.

154. Barden AE, Mas E, Mori TA. n-3 Fatty acid supplementation and proresolving mediators of inflammation. Curr Opin Lipidol. 2016;27(1):26-32.

155. Fredman G, et al. An imbalance between specialized pro-resolving lipid mediators and pro-inflammatory leukotrienes promotes instability of atherosclerotic plaques. Nat Commun. 2016;7:12859.

156.Sasaki A, et al. Determination of $\omega-6$ and $\omega-3$ PUFA metabolites in human urine samples using UPLC/MS/MS. Anal Bioanal Chem. 2015;407(6):1625-1639.

157. Rathod KS, et al. Accelerated resolution of inflammation underlies sex differences in inflammatory responses in humans. J Clin Invest. 2017;127(1):169-182.

158. Ramsden CE, et al. Targeted alteration of dietary $\mathrm{n}-3$ and $\mathrm{n}-6$ fatty acids for the treatment of chronic headaches: a randomized trial. Pain. 2013;154(11):2441-2451.

159. Dalli J, et al. Human sepsis eicosanoid and proresolving lipid mediator temporal profiles: correlations with survival and clinical outcomes. Crit Care Med. 2017;45(1):58-68.

160.See VHL, et al. Effects of prenatal n-3 fatty acid supplementation on offspring resolvins at birth and 12 years of age: a double-blind, randomised controlled clinical trial. Br J Nutr. 2017;118(11):971-980.

161. See VHL, et al. Effects of postnatal omega-3 fatty acid supplementation on offspring pro-resolving mediators of inflammation at 6 months and 5 years of age: a double blind, randomized controlled clinical trial. Prostaglandins Leukot Essent Fatty Acids. 2017;126:126-132.

162.Keelan JA, et al. Effects of maternal n-3 fatty acid supplementation on placental cytokines, pro-resolving lipid mediators and their precursors. Reproduction. 2015;149(2):171-178.

163. Mozurkewich EL, et al. Pathway markers for pro-resolving lipid mediators in maternal and umbilical cord blood: a secondary analysis of the Mothers, Omega-3, and Mental Health Study. Front Pharmacol. 2016;7:274.

164.Elliott E, Hanson CK, Anderson-Berry AL, Nordgren TM. The role of specialized pro-resolving mediators in maternal-fetal health. Prostaglandins Leukot Essent Fatty Acids. 2017;126:98-104.

165. Arnardottir H, Orr SK, Dalli J, Serhan CN. Human milk proresolving mediators stimulate resolution of acute inflammation. Mucosal Immunol. 2016;9(3):757-766.

166.Weiss GA, Troxler H, Klinke G, Rogler D, Braegger C, Hersberger M. High levels of anti-inflammatory and pro-resolving lipid mediators lipoxins and resolvins and declining docosahexaenoic acid levels in human milk during the first month of lactation. Lipids Health Dis. 2013;12:89.

167. Ramaswami R, Serhan CN, Levy BD, Makrides M. Fish oil supplementation in pregnancy. $N$ Engl JMed. 2016;375(26):2599-2601.
168. Arita M, et al. Metabolic inactivation of resolvin E1 and stabilization of its anti-inflammatory actions. J Biol Chem. 2006;281(32):22847-22854.

169. De Caterina R. n-3 Fatty acids in cardiovascular disease. N Engl JMed. 2011;364(25):2439-2450.

170.Del Gobbo LC, et al. $\omega-3$ Polyunsaturated fatty acid biomarkers and coronary heart disease: pooling project of 19 cohort studies. JAMA Intern Med. 2016;176(8):1155-1166.

171. Back M. Omega-3 fatty acids in atherosclerosis and coronary artery disease. Future Sci OA. 2017;3(4):Fso236

172. Elabdeen HR, Mustafa M, Szklenar M, Rühl R, Ali R, Bolstad AI. Ratio of pro-resolving and pro-inflammatory lipid mediator precursors as potential markers for aggressive periodontitis. PLoS One. 2013;8(8):e70838.

173. Barden $\mathrm{AE}$, et al. A randomized trial of effects of alcohol on cytochrome $\mathrm{P} 450$ eicosanoids, mediators of inflammation resolution, and blood pressure in men. Alcohol Clin Exp Res. 2017;41(10):1666-1674.

174. Polus A, et al. Omega-3 fatty acid supplementation influences the whole blood transcriptome in women with obesity, associated with proresolving lipid mediator production. Biochim Biophys Acta. 2016;1861(11):1746-1755.

175. Hecker M, et al. Immunomodulation by lipid emulsions in pulmonary inflammation: a randomized controlled trial. Crit Care. 2015;19:226.

176. de la Rosa X, Norris PC, Chiang N, Rodriguez AR, Spur BW, Serhan CN. Identification and complete stereochemical assignments of the new Resolvin Conjugates in Tissue Regeneration (RCTR) in human tissues that stimulate proresolving phagocyte functions and tissue regeneration. Am J Pathol. 2018;188(4):950-966.

177. Clish CB, Levy BD, Chiang N, Tai HH, Serhan $\mathrm{CN}$. Oxidoreductases in lipoxin A4 metabolic inactivation: a novel role for 15-onoprostaglandin 13-reductase/leukotriene B4 12-hydroxydehydrogenase in inflammation. J Biol Chem. 2000;275(33):25372-25380.

178. Lance KD, et al. Unidirectional and sustained delivery of the proresolving lipid mediator resolvin D1 from a biodegradable thin film device. J Biomed Mater Res A. 2017;105(1):31-41.

179. Orr SK, Colas RA, Dalli J, Chiang N, Serhan $\mathrm{CN}$. Proresolving actions of a new resolvin D1 analog mimetic qualifies as an immunoresolvent. Am J Physiol Lung Cell Mol Physiol. 2015;308(9):L904-L911.

180. Resolvyx Pharmaceuticals Inc. Safety and efficacy study of RX-10045 on the signs and symptoms of dry eye. ClinicalTrials.gov Website. https:// clinicaltrials.gov/ct2/show/NCT00799552. Accessed March 27, 2018.

181. Science Blog. Resolvyx announces positive data - phase 2 trial of resolvin RX-10045 for dry eye syndrome. https://scienceblog.com/24358/ resolvyx-announces-positive-data-phase-2-trial-ofresolvin-rx-10045-for-dry-eye-syndrome/. 2009.

182. The Forsyth Institute. Safety and Preliminary Efficacy of Lipoxin Analog BLXA4-ME Oral Rinse for the Treatment of Gingivitis (BLXA4). ClinicalTrials.gov Website. https:// clinicaltrials.gov/ct2/show/NCT02342691. Accessed March 27, 2018.
183. Reátegui E, et al. Microscale arrays for the profiling of start and stop signals coordinating human-neutrophil swarming. Nat Biomed Eng. 2017;1:0094.

184. Motwani MP, et al. Potent anti-inflammatory and pro-resolving effects of anabasum in a human model of self-resolving acute inflammation [published online ahead of print December 14, 2017]. Clin Pharmacol Ther. https://doi. org/10.1002/cpt.980.

185. Hu J, et al. Dexmedetomidine prevents cognitive decline by enhancing resolution of high mobility group box 1 protein-induced inflammation through a vagomimetic action in mice [published online ahead of print December 18, 2017]. Anesthesiology. https://doi.org/10.1097/ ALN.0000000000002038.

186.Uno H, et al. Immunonutrition suppresses acute inflammatory responses through modulation of resolvin $\mathrm{E} 1$ in patients undergoing major hepatobiliary resection. Surgery. 2016;160(1):228-236.

187. Elajami TK, Colas RA, Dalli J, Chiang N, Serhan CN, Welty FK. Specialized proresolving lipid mediators in patients with coronary artery disease and their potential for clot remodeling. FASEB J. 2016;30(8):2792-2801.

188. Erdman J, Oria M, Pillsbury L, eds. Nutrition and traumatic brain injury: improving acute and subacute health outcomes in military personnel. Washington, DC, USA: National Academies Press; 2011.

189. Sulciner ML, et al. Resolvins suppress tumor growth and enhance cancer therapy. JExp Med. 2018;215(1):115-140.

190.Zhong X, Lee HN, Surh YJ. RvD1 inhibits TNF $\alpha$-induced c-Myc expression in normal intestinal epithelial cells and destabilizes hyperexpressed c-Myc in colon cancer cells. Biochem Biophys Res Commun. 2018;496(2):316-323.

191. Christ A, et al. Western diet triggers NLRP3dependent innate immune reprogramming. Cell. 2018;172(1-2):162-175.e14.

192.Lee S, et al. NLRP3 inflammasome deficiency protects against microbial sepsis via increased lipoxin B4 synthesis. Am J Respir Crit Care Med. 2017;196(6):713-726.

193. López-Vicario C, et al. Association of a variant in the gene encoding for ERV1/ChemR23 with reduced inflammation in visceral adipose tissue from morbidly obese individuals. Sci Rep. 2017;7(1):15724.

194. Gromovsky AD, et al. $\Delta-5$ fatty acid desaturase FADS1 impacts metabolic disease by balancing proinflammatory and proresolving lipid mediators. Arterioscler Thromb Vasc Biol. 2018;38(1):218-231.

195.Lee CT, et al. Resolvin E1 reverses experimental periodontitis and dysbiosis. JImmunol. 2016;197(7):2796-2806.

196.Arita M, et al. Resolvin E1, an endogenous lipid mediator derived from omega-3 eicosapentaenoic acid, protects against 2,4,6-trinitrobenzene sulfonic acid-induced colitis. Proc Natl Acad Sci U S A. 2005;102(21):7671-7676.

197. Bohr S, Patel SJ, Sarin D, Irimia D, Yarmush ML, Berthiaume F. Resolvin D2 prevents secondary thrombosis and necrosis in a mouse burn wound model. Wound Repair Regen. 2013;21(1):35-43.

198.Eritja N, et al. Tumour-microenvironmental 
blood flow determines a metabolomic signature identifying lysophospholipids and resolvin D as biomarkers in endometrial cancer patients. Oncotarget. 2017;8(65):109018-109026.
199. Prevete N, et al. Formyl peptide receptor 1 suppresses gastric cancer angiogenesis and growth by exploiting inflammation resolution pathways. Oncoimmunology. 2017;6(4):e1293213.
200.Hersberger M. Potential role of the lipoxygenase derived lipid mediators in atherosclerosis: leukotrienes, lipoxins and resolvins. Clin Chem Lab Med. 2010;48(8):1063-1073. 